\title{
Estrone-induced biochemical and molecular changes confers tolerance to boron toxicity in wheat seedlings
}

\author{
Serkan ERDAL ${ }^{1}$, Mucip GENIŞEL ${ }^{2}$, Hulya TURK ${ }^{1}$ \\ ${ }^{1}$ Biology Department, Science Faculty, Ataturk University, Erzurum, Turkey \\ ${ }^{2}$ Department of Crop and Animal Production, Vocational High School, Agri ,Turkey
}

\begin{abstract}
To determine the effects of estrone on the ability of plants to tolerate boron toxicity, estrone $(0.01 \mu \mathrm{M})$ and boron $\left(5 \mathrm{mM} \mathrm{H}_{3} \mathrm{BO}_{3}\right)$, singly or in combination, were exogenously applied to 11-d-wheat seedlings and 3 days later from treatments, they were harvested to determine many parameters. Boron toxicity caused to remarkable reductions on the root and shoot lengths. Besides, it led to a marked decrease in the activities of antioxidant enzymes, including superoxide dismutase (SOD), guaiacol peroxidase (GPX), catalase (CAT), ascorbate peroxidase (APX) and glutathione reductase (GR), as well as an decrease in the level of soluble protein and photosynthetic pigments including chlorophyll and carotene. Thus, boron toxicity bring about a significant oxidative injury by increasing levels of the superoxide anion $\left(\mathrm{O}_{2}^{-}\right)$, hydrogen peroxide $\left(\mathrm{H}_{2} \mathrm{O}_{2}\right)$ and malondialdehyde (MDA). Whereas estrone was able to reduce the boron-induced oxidative damage and improved the antioxidant system. Moreover, the effects of boron toxicity on genetic material were also determined using the RAPD (randomly amplified polymorphic DNA) technique. While boron led to DNA damage in wheat seedlings, estrone significantly mitigated this damage. Element analysis demonstrated that estrone did not prevent boron uptake by roots, whereas it did stimulate the transportation of lead from roots to leaves. Taken together, our data demonstrate a versatile manner for the first time that estrone-induced boron tolerance is associated with many biochemical and molecular mechanisms, including the antioxidant system, ROS detoxification, modulation of uptake and transportation of boron and protection of genetic material.
\end{abstract}

Keywords: wheat, boron toxicity, oxidative stress, antioxidant enzymes, DNA mutations 